\title{
Exploring Energy Transfer in Luminescent Heterometallic Ruthenium- Iridium Ion Pairs
}

\author{
Martina Sandroni ${ }^{\dagger}$ and Eli Zysman-Colman** \\ †Département de Chimie, Université de Sherbrooke, 2500 Boul. de 1’Université, Sherbrooke, QC, Canada, J1K 2R1 \\ ¥EaStCHEM School of Chemistry, University of St Andrews, St Andrews, Fife, UK, KY16 9ST, Fax: +44-1334 463808; Tel: +44- \\ 1334 463826, E-mail: ezc@st-andrews.ac.uk; URL: http://www.zysman-colman.com
}

\section{SUPPORTING INFORMATION}

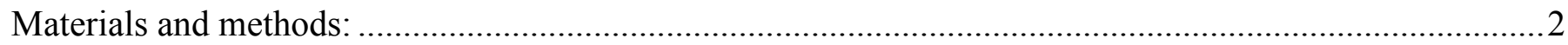

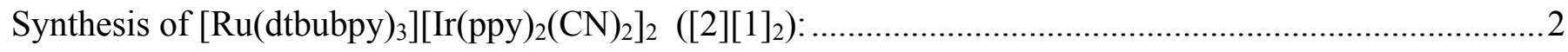

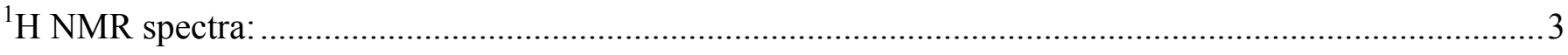

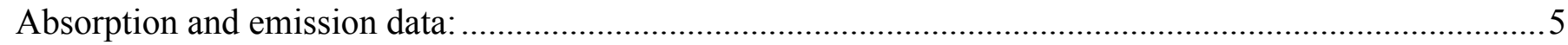

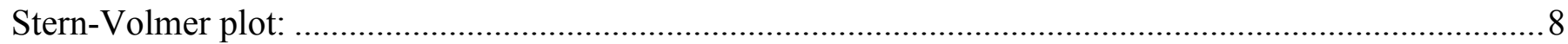

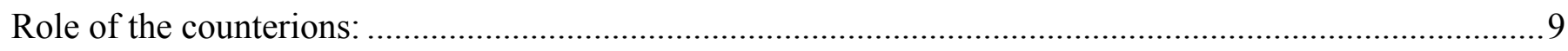

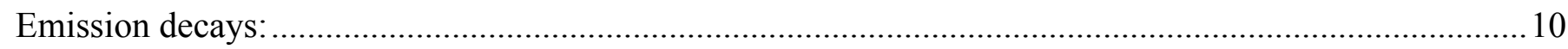

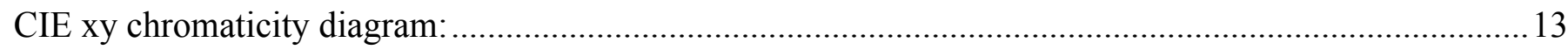

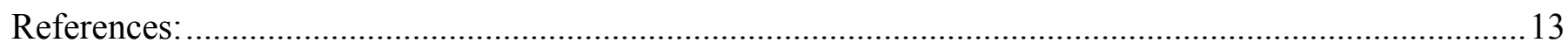




\section{Materials and methods:}

All the reagents were purchased by Sigma Aldrich or Oakwood Chemicals and were used without further purification. TBA[Ir(ppy $\left.)_{2}(\mathrm{CN})_{2}\right](\mathbf{T B A}[\mathbf{1}]),{ }^{1}$ and $\left[\mathrm{Ru}(\mathrm{dtbubpy})_{3}\right] \mathrm{Cl}_{2},\left([\mathbf{2}] \mathbf{C l}_{2}\right),{ }^{2}$ were synthesized according to previously reported procedures, and the spectroscopic and MS data matched those found in the literature. ${ }^{1} \mathrm{H}$ NMR spectra were recorded on a Bruker Avance spectrometer at $400 \mathrm{MHz}$, the chemical shifts are referred to the residual peak of the solvent. The following abbreviations have been used for multiplicity assignments: "s" for singlet, "d" for doublet, "t" for triplet, "m" for multiplet.

High resolution mass spectrometry measurements were performed on a quadrupole time-of-flight (ES-QTOF), model Synapt MS G1 from Waters in positive electrospray mode.

The films used for the photophysical measurements in the solid state were prepared by the drop-cast technique. A drop of the solution of $\left[\mathrm{Ru}(\mathrm{dtbubpy})_{3}\right]\left[\operatorname{Ir}(\mathrm{ppy})_{2}(\mathrm{CN})_{2}\right]_{2}$ in a polar solvent such as ethanol or acetonitrile was deposited on a clean glass plate and allowed to dry. The films were then further dried at $50{ }^{\circ} \mathrm{C}$ for 20 minutes and then allowed to cool to room temperature before performing the measurements.

For photophysical measurements, all samples were prepared in $\mathrm{HPLC}$ grade $\left(\mathrm{CH}_{3} \mathrm{CN}, \mathrm{CH}_{2} \mathrm{Cl}_{2}, \mathrm{MeOH}\right.$, $\mathrm{EtOH}$ ) or distilled (2-MeTHF) solvents, with concentrations of the order of $25 \mu \mathrm{M}$. Absorption spectra were recorded at room temperature in a $1.0 \mathrm{~cm}$ capped quartz cuvette, using a Shimadzu UV-1800 double beam spectrophotometer. Molar absorptivity determination was verified by linear least-squares fit of values obtained from at least three independent solutions at varying concentrations with absorbances ranging from 0.01 to 1.5 .

Steady-state emission spectra were obtained by exciting at the longest wavelength absorption maxima using a Horiba Jobin Yvon Fluorolog-3 spectrofluorometer equipped with double monochromators and a photomultiplier tube detector (Hamamatsu model R955). Emission quantum yields were determined using the optically dilute method. ${ }^{3}$

Lifetime measurements were done with an Edinburgh Instruments Mini Tau lifetime fluorimeter with an EPL 405 laser (exciting at $405 \mathrm{~nm}$ ). The solutions were freshly prepared before the measurements and the absorbance was between 0.06 and 0.09 at the excitation wavelength. The emission range was selected through filters having a $50 \mathrm{~nm}$ bandpass (the wavelengths are specified for every measurement). The lifetime of $\left.[\mathrm{Ru} \text { (dtbubpy) })_{3}\right]\left(\mathrm{PF}_{6}\right)_{2}$ in 2-MeTHF (Table 1) was measured using a the time-correlated single photon counting (TCSPC) option of the Jobin Yvon Fluorolog-3 spectrofluorometer. The sample was excited by a pulsed NanoLED at $341 \mathrm{~nm}$ (pulse duration $<1 \mathrm{~ns}$; fwhm $=14 \mathrm{~nm}$ ).

\section{Synthesis of [Ru(dtbubpy $\left.)_{3}\right]\left[\operatorname{Ir}(\mathrm{ppy})_{2}(\mathrm{CN})_{2}\right]_{2} \quad\left([2][1]_{2}\right)$ :}

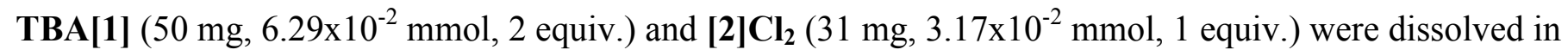
$20 \mathrm{~mL}$ of $\mathrm{CH}_{2} \mathrm{Cl}_{2}$. The red solution was then washed eight times with water, until the signal of the TBA 
cation was no longer detectible in the ${ }^{1} \mathrm{H}$ NMR spectrum. The organic solvent was then removed to afford 63 mg of a red powder. Yield: $99 \%$. X-ray quality crystals were obtained by vapour diffusion of tertbutylmethyl ether (TBME) in an acetonitrile solution of the salt.

${ }^{1}$ H NMR (400 MHz, $\left.\mathbf{C D}_{3} \mathbf{C N}, \mathbf{2 5}^{\circ} \mathbf{C}\right): \delta=9.64(\mathrm{dm}, 4 \mathrm{H}, \mathrm{J}=5.9 \mathrm{~Hz}), 8.48(\mathrm{~d}, 6 \mathrm{H}, \mathrm{J}=1.7 \mathrm{~Hz}), 7.95(\mathrm{~d}, 4 \mathrm{H}$, $8.0 \mathrm{~Hz}), 7.83(\mathrm{~m}, 4 \mathrm{H}), 7.62(\mathrm{dd}, 4 \mathrm{H}, \mathrm{J}=8.0 \mathrm{~Hz}, \mathrm{~J}=0.8 \mathrm{~Hz}), 7.55(\mathrm{~d}, 6 \mathrm{H}, \mathrm{J}=6.0 \mathrm{~Hz}), 7.38(\mathrm{dd}, 6 \mathrm{H}, \mathrm{J}=6.0$ $\mathrm{Hz}, \mathrm{J}=2.0 \mathrm{~Hz}), 7.21(\mathrm{~m}, 4 \mathrm{H}), 7.78(\mathrm{~m}, 4 \mathrm{H}), 6.68(\mathrm{td}, 4 \mathrm{H}, \mathrm{J}=7.4 \mathrm{~Hz}, \mathrm{~J}=1.2 \mathrm{~Hz}), 6.19(\mathrm{dm}, 4 \mathrm{H}, \mathrm{J}=7.4 \mathrm{~Hz})$, $1.38(\mathrm{~s}, 54 \mathrm{H}) \mathrm{ppm}$.

${ }^{13}$ C NMR (100 MHz, $\left.\mathbf{C D}_{3} \mathbf{C N}, 25{ }^{\circ} \mathrm{C}\right): \delta=169.73,166.64,165.49,163.72,158.29,155.13,152.12,146.06$, $137.38,132.50,129.99,125.92,125.02,123.97,122.90,121.70,120.26,36.71,30.90 \mathrm{ppm}$.

HR-MS (ESI $\left.{ }^{+}\right)$: Found $\mathrm{m} / \mathrm{z}=453.2447$; calculated for $\left(\mathrm{C}_{54} \mathrm{H}_{72} \mathrm{~N}_{6} \mathrm{Ru}\right),[2]^{2+} \mathrm{m} / \mathrm{z}=453.2433$.

HR-MS (ESI'): Found $\mathrm{m} / \mathrm{z}=553.0972$; calculated for $\left(\mathrm{C}_{24} \mathrm{H}_{16} \mathrm{IrN}_{4}\right),[1]^{-} \mathrm{m} / \mathrm{z}=553.0999$.

\section{${ }^{1} \mathrm{H}$ NMR spectra:}

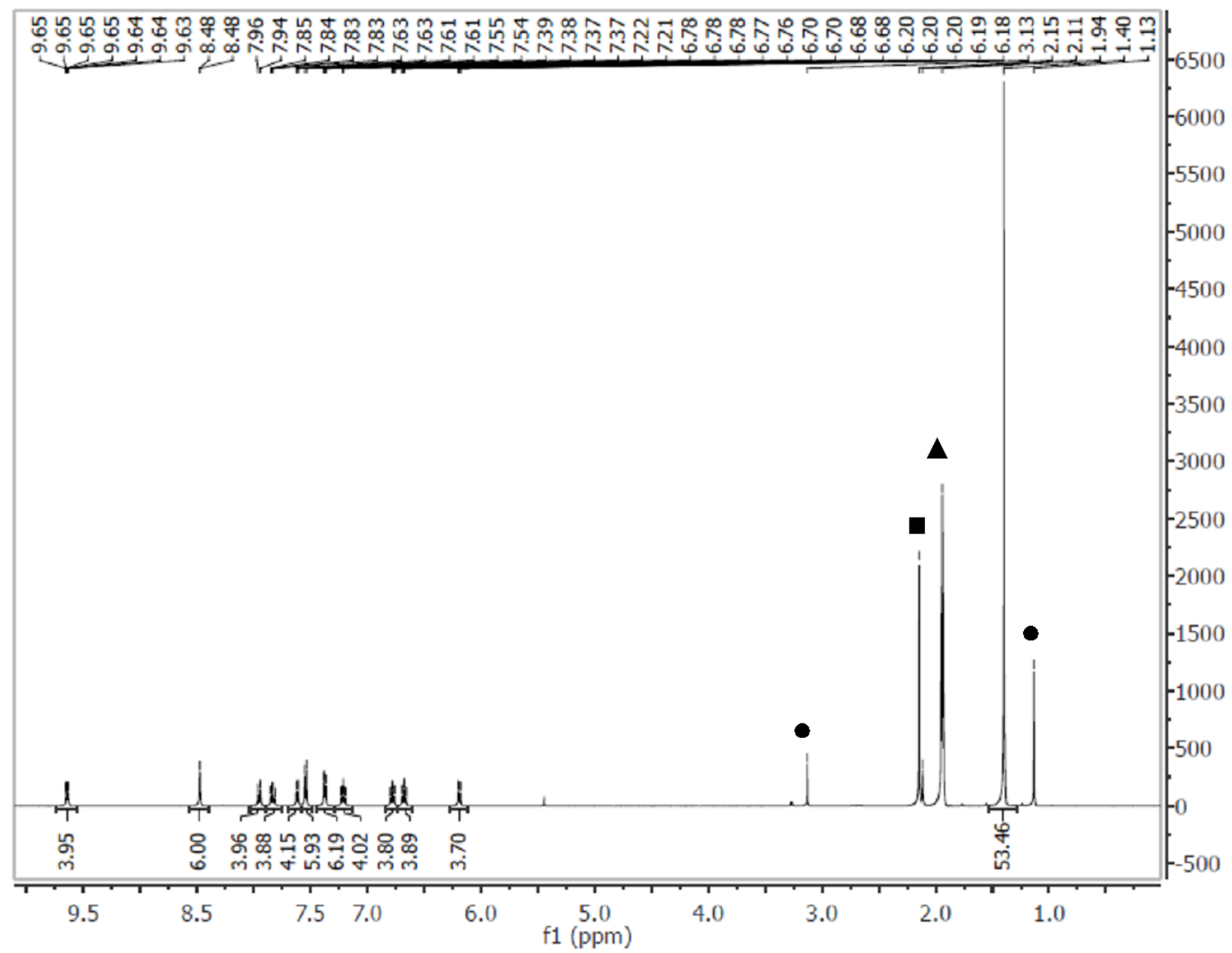

Figure S1. ${ }^{1} \mathrm{H}-\mathrm{NMR}$ spectrum of $[2][1]_{2}$, recorded at $25{ }^{\circ} \mathrm{C}$ in $\mathrm{CD}_{3} \mathrm{CN}$. $\bullet$ tert-butylmethyl ether, cocrystallized with the mixed salt; $\boldsymbol{\square}$ water; $\boldsymbol{\Delta} \mathrm{CH}_{3} \mathrm{CN}$. 


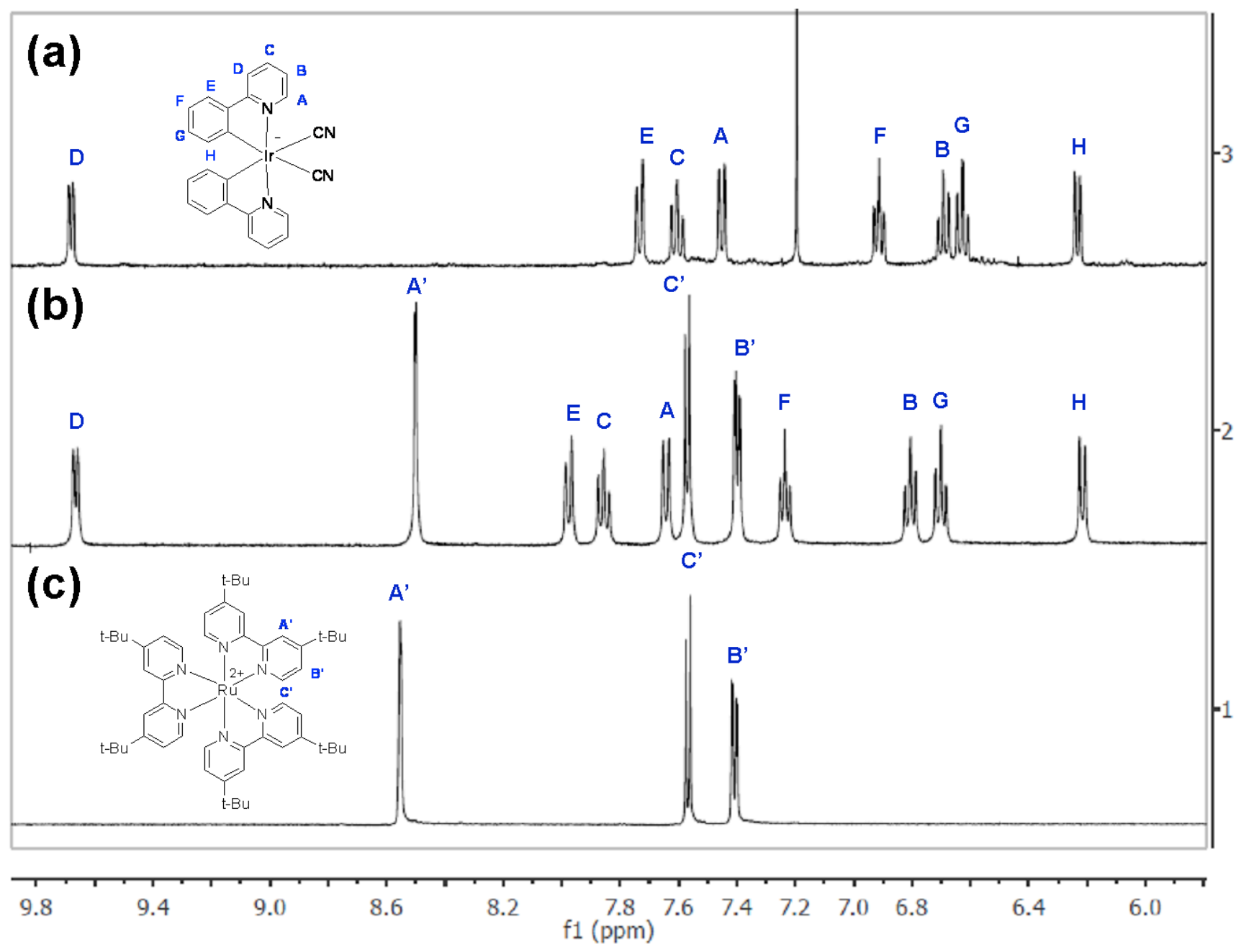

Figure S2. Superposition of the aromatic part of the ${ }^{1} \mathrm{H}$ NMR spectra of TBA[1] (a, $\left.\mathrm{CDCl}_{3}\right)[2][1]_{2}$ (b, $\left.\mathrm{CD}_{3} \mathrm{CN}\right)$ and $[2] \mathbf{C l}_{2}\left(\mathrm{c}, \mathrm{CD}_{3} \mathrm{CN}\right)$. The spectrum of TBA[1] was attributed by comparison with the spectrum of $\left[\operatorname{Ir}(\mathrm{ppy})_{2}(\mathrm{CN})_{2}\right]^{-4}$ 


\section{Absorption and emission data:}

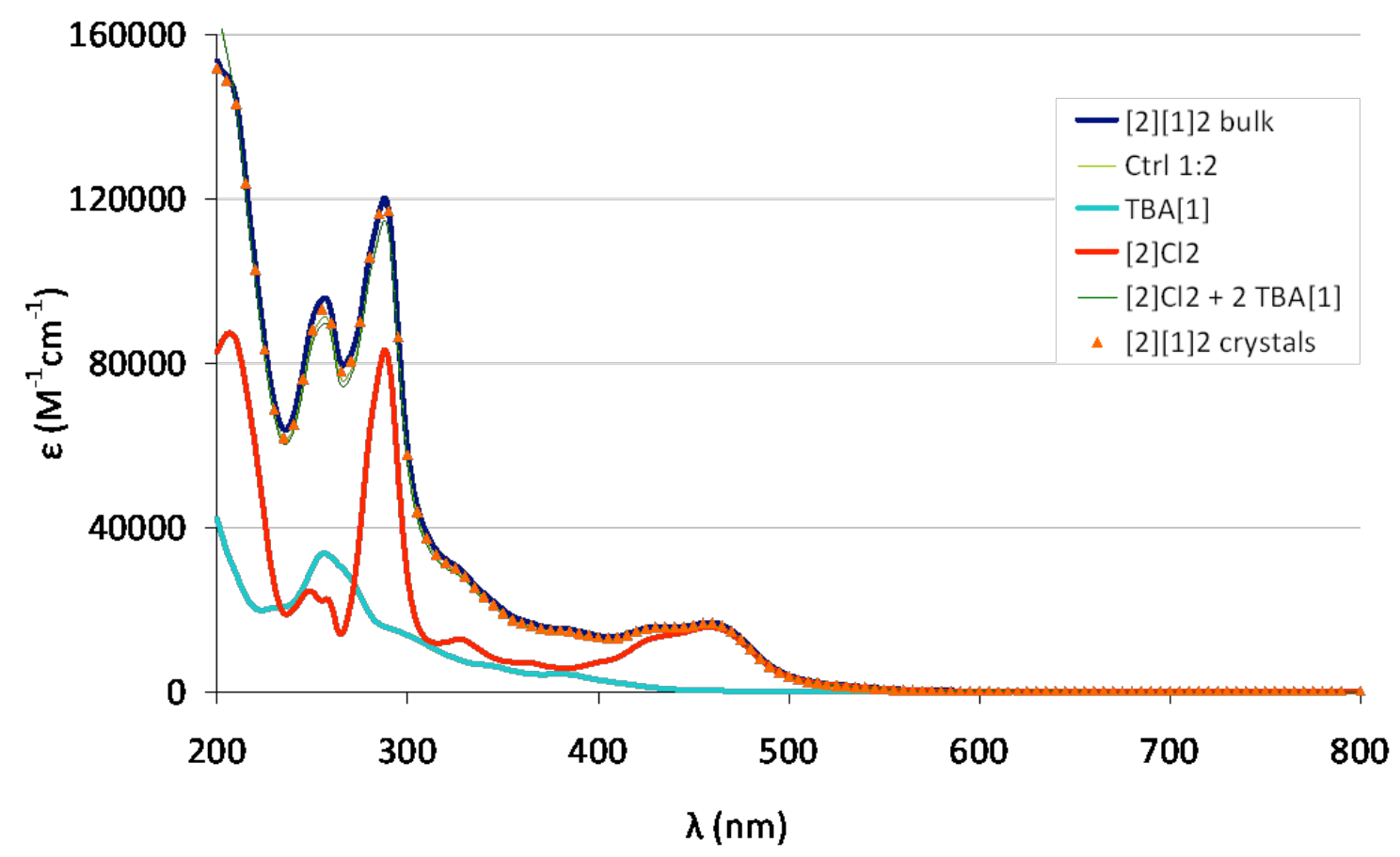

Figure S3. Absorption spectra of the mixed salt and model complexes in acetonitrile at room temperature, superposed with those of the control solution containing one equivalent of [2] $\mathbf{C l}_{\mathbf{2}}$ and two equivalents of TBA[1] (Ctrl 1:2), with the mathematical sum of the spectra of the two model complexes ([2] $\left.\mathbf{C l}_{\mathbf{2}}+\mathbf{T B A}[\mathbf{1}]\right)$ and with the spectrum of the crystals. 

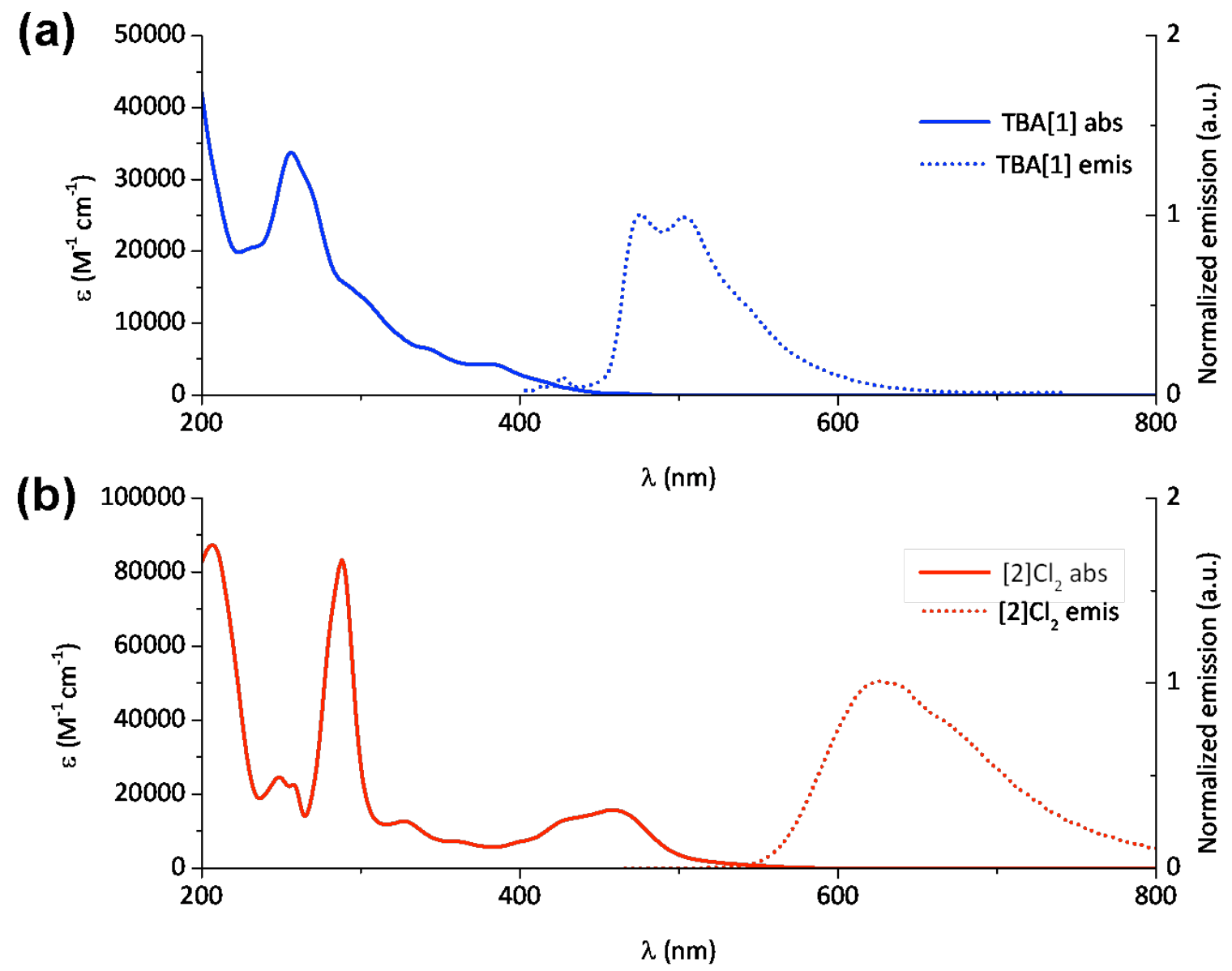

Figure S4. Absorption and emission spectra of the model compounds $\mathbf{T B A}[\mathbf{1}]$ (a) and $[\mathbf{2}] \mathbf{C l}_{\mathbf{2}}$ (b), recorded at room temperature in acetonitrile. 
Table S1. Absorption and emission data for the model compounds $\mathbf{T B A}[\mathbf{1}]$ and $[\mathbf{2}] \mathbf{C l}_{\mathbf{2}}$, and for the soft salt [2][1 $]_{2}$ and a 1:2 mixture of [2] $\mathbf{C l}_{\mathbf{2}}: \mathbf{T B A}[\mathbf{1}]$ in different solvents. The lifetime values, obtained by timeresolved measurements, are reported in Table 1 in the text of the communication.

\begin{tabular}{|c|c|c|c|c|}
\hline & \multirow[t]{2}{*}{ Solvent } & \multirow[t]{2}{*}{$\lambda_{\text {abs }} / \mathbf{n m}\left(\varepsilon / \mathbf{M}^{-1} \mathbf{c m}^{-1}\right)$} & \multicolumn{2}{|c|}{$\lambda_{\mathrm{em}} / \mathbf{n m}$} \\
\hline & & & $\mathbf{I r}(+\mathbf{R u})^{\mathrm{c}}$ & $\mathbf{R} \mathbf{u}^{\mathrm{d}}$ \\
\hline \multirow[t]{4}{*}{ TBA[1] } & $\mathrm{MeOH} / \mathrm{EtOH}^{\mathrm{a}}$ & $250 ; 265 ; 371 ; 455$ & $467 ; 497$ & - \\
\hline & $\mathrm{CH}_{3} \mathrm{CN}$ & $256\left(3.910^{4}\right) ; 379\left(4.510^{3}\right) ; 461\left(2.210^{2}\right)$ & $477 ; 506$ & - \\
\hline & $\mathrm{CH}_{2} \mathrm{Cl}_{2}$ & $259 ; 382 ; 460$ & $473 ; 504$ & - \\
\hline & 2-MeTHF & $257 ; 388 ; 462$ & $479 ; 509$ & - \\
\hline \multirow[t]{4}{*}[2]{$\mathrm{Cl}_{2}$} & $\mathrm{MeOH} / \mathrm{EtOH} \mathrm{a}^{\mathrm{a}}$ & $249 ; 258 ; 288 ; 326 ; 458$ & - & 625 \\
\hline & $\mathrm{CH}_{3} \mathrm{CN}$ & $\begin{array}{c}208\left(8.610^{4}\right) ; 248\left(2.410^{4}\right) ; 258\left(2.210^{4}\right) ; 288(7.8 \\
\left.10^{4}\right) ; 327\left(1.310^{4}\right) ; 458\left(1.610^{4}\right)\end{array}$ & - & 630 \\
\hline & $\mathrm{CH}_{2} \mathrm{Cl}_{2}$ & $249 ; 259 ; 290 ; 327 ; 464$ & - & 617 \\
\hline & $2-M e T H F$ & $249 ; 258 ; 289 ; 326 ; 461^{\mathrm{b}}$ & - & $642^{\mathrm{b}}$ \\
\hline \multirow[t]{5}{*}[2]{$[1]_{2}$} & $\mathrm{MeOH} / \mathrm{EtOH} \mathrm{a}^{\mathrm{a}}$ & $250 ; 288 ; 458$ & $466 ; 497 ; 624$ & 625 \\
\hline & $\mathrm{CH}_{3} \mathrm{CN}$ & $257\left(9.510^{4}\right) ; 288\left(1.210^{5}\right) ; 433\left(1.610^{4}\right) ; 459(1.7$ & $475 ; 505 ; 625$ & 627 \\
\hline & $\mathrm{CH}_{2} \mathrm{Cl}_{2}$ & $259 ; 289 ; 436 ; 465$ & $473 ; 504 ; 614$ & 617 \\
\hline & 2-MeTHF & $258 ; 290 ; 433$ & $477 ; 505 ; 660$ & 663 \\
\hline & Film & - & - & 638 \\
\hline Ctrl 1:2 & $\mathrm{CH}_{3} \mathrm{CN}$ & $257\left(9.210^{4}\right) ; 288\left(1.210^{5}\right) ; 427\left(1.510^{4}\right) ; 459(1.6$ & $478 ; 504 ; 624$ & 628 \\
\hline
\end{tabular}

${ }^{a}$ Solvents in a 1:1 ratio; ${ }^{b}$ spectrum of $\left[\mathrm{Ru}(\mathrm{dtbubpy})_{3}\right]\left(\mathrm{PF}_{6}\right)_{2}$, the chloride salt is insoluble in 2-

MeTHF; ${ }^{c} \lambda_{\text {exc }}=390 \mathrm{~nm} ;{ }^{d} \lambda_{\text {exc }}$ at the maximum of the ${ }^{1}$ MLCT absorption band. 


\section{Stern-Volmer plot:}

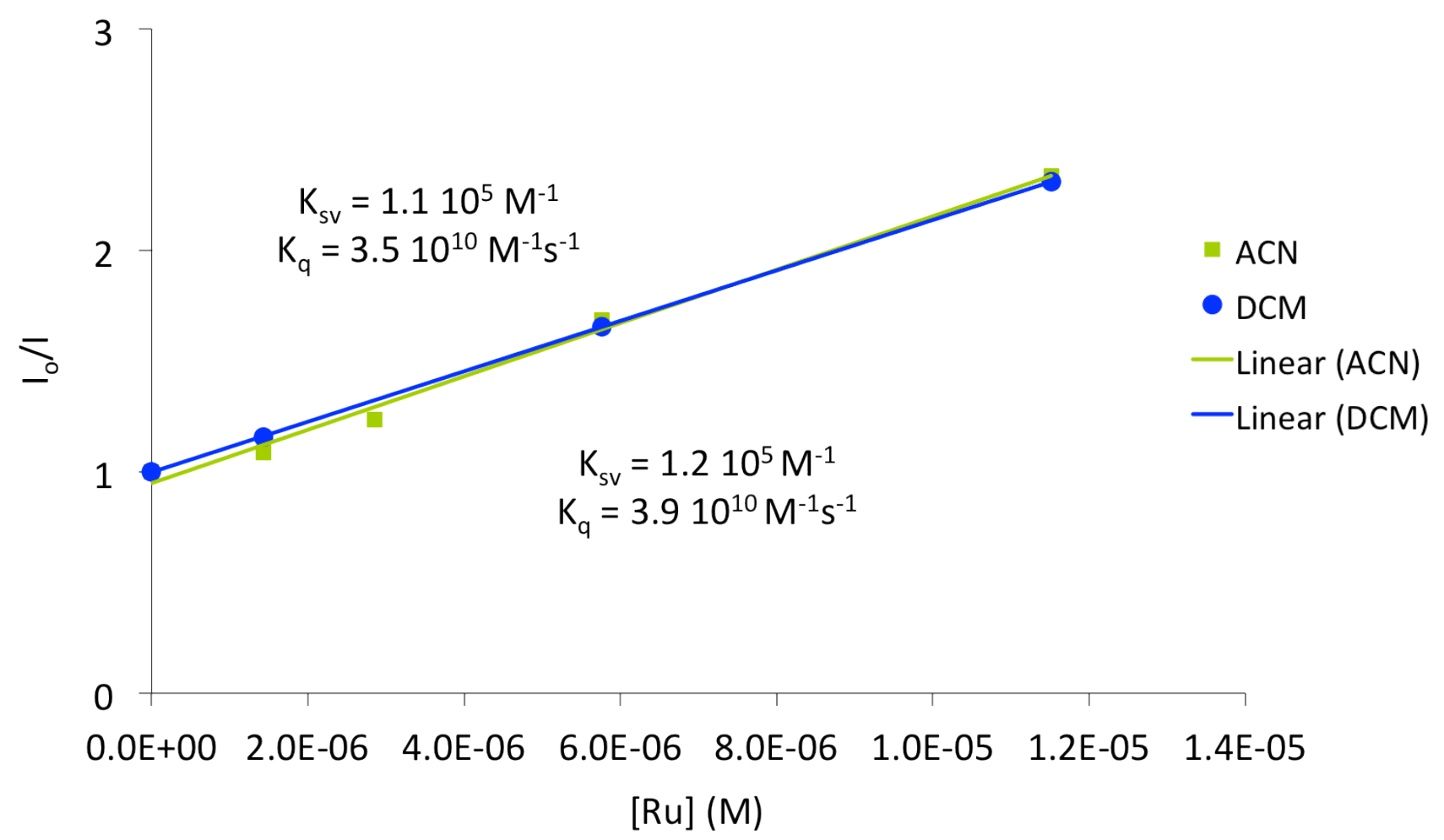

Figure S5. Stern-Volmer plots recorded in acetonitrile ( $\square$; linear -$)$ and dichloromethane $(\bullet ;$ linear -$)$. The

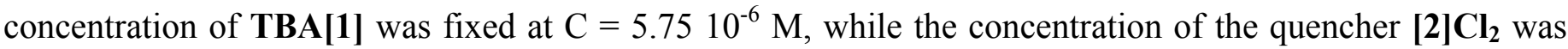
gradually increased. The intensity of the iridium emission was then plotted against the quencher concentration. At $\mathrm{C}_{[2] \mathrm{Cl} 2}>1.210^{-5} \mathrm{M}$, strong deviations from linearity were observed in both solvents. This phenomenon is due to the superposition of the emission of the iridium salt and the absorption of the ruthenium MLCT band, which artificially decreases the emission intensity. In order to attenuate this artefact even at $\mathrm{C}_{[2] \mathrm{Cl} 2}<1.210^{-5} \mathrm{M}$, only the intensity of the emission band at $504 \mathrm{~nm}$ was considered (at this wavelength the absorption of the ruthenium complex becomes negligible at low concentrations). 


\section{Role of the counterions:}
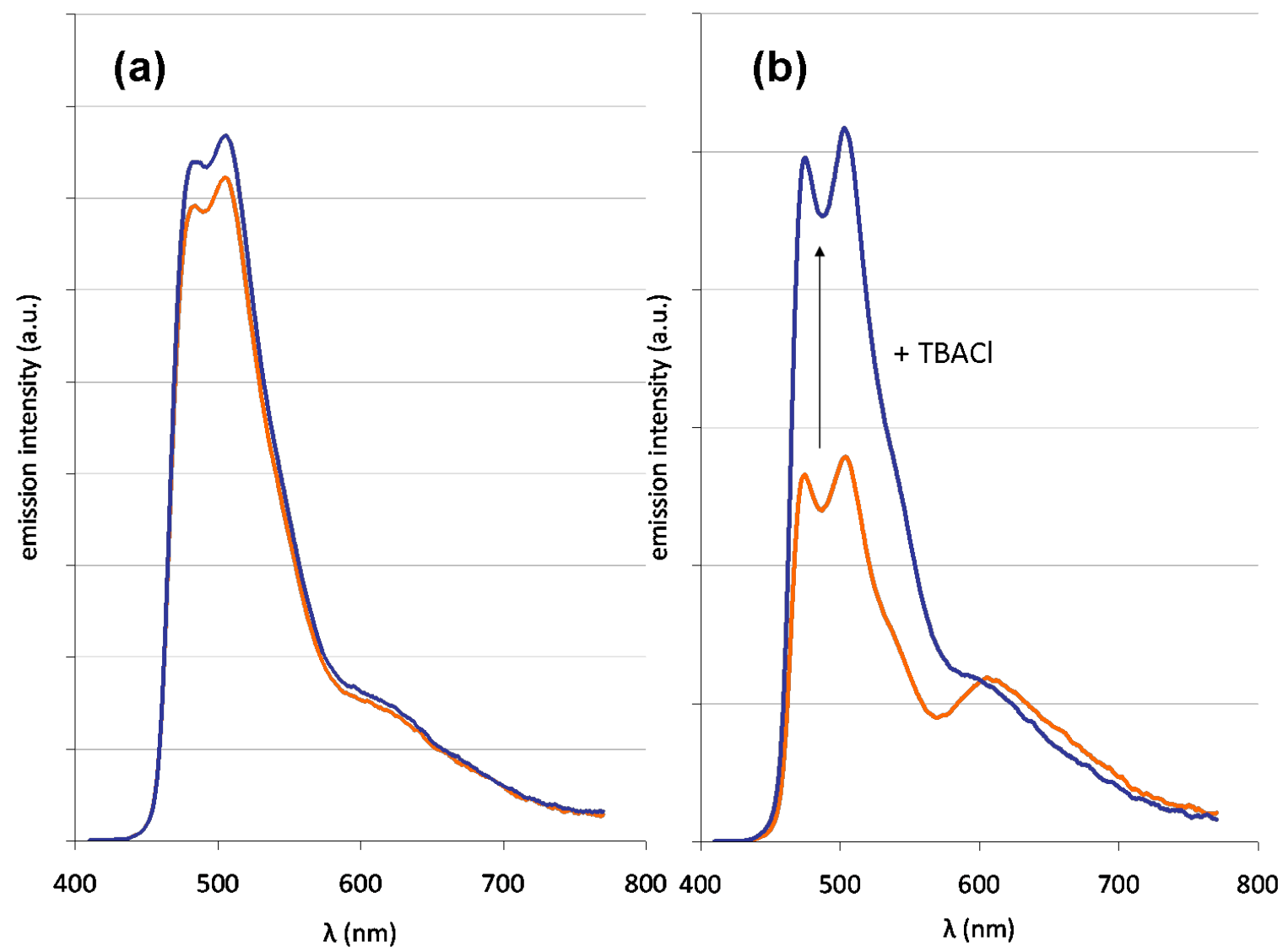

Figure S6. Effect of the addition of 2 equivalents of TBACl to a solution of $[2][1]_{2}\left(\mathrm{C}=5.7510^{-6} \mathrm{M}\right)$ in acetonitrile (a) or dichloromethane (b). Solution of $[2][1]_{2}(-) ;[2][1]_{2}+\mathrm{TBACl}(-)$. 


\section{Emission decays:}

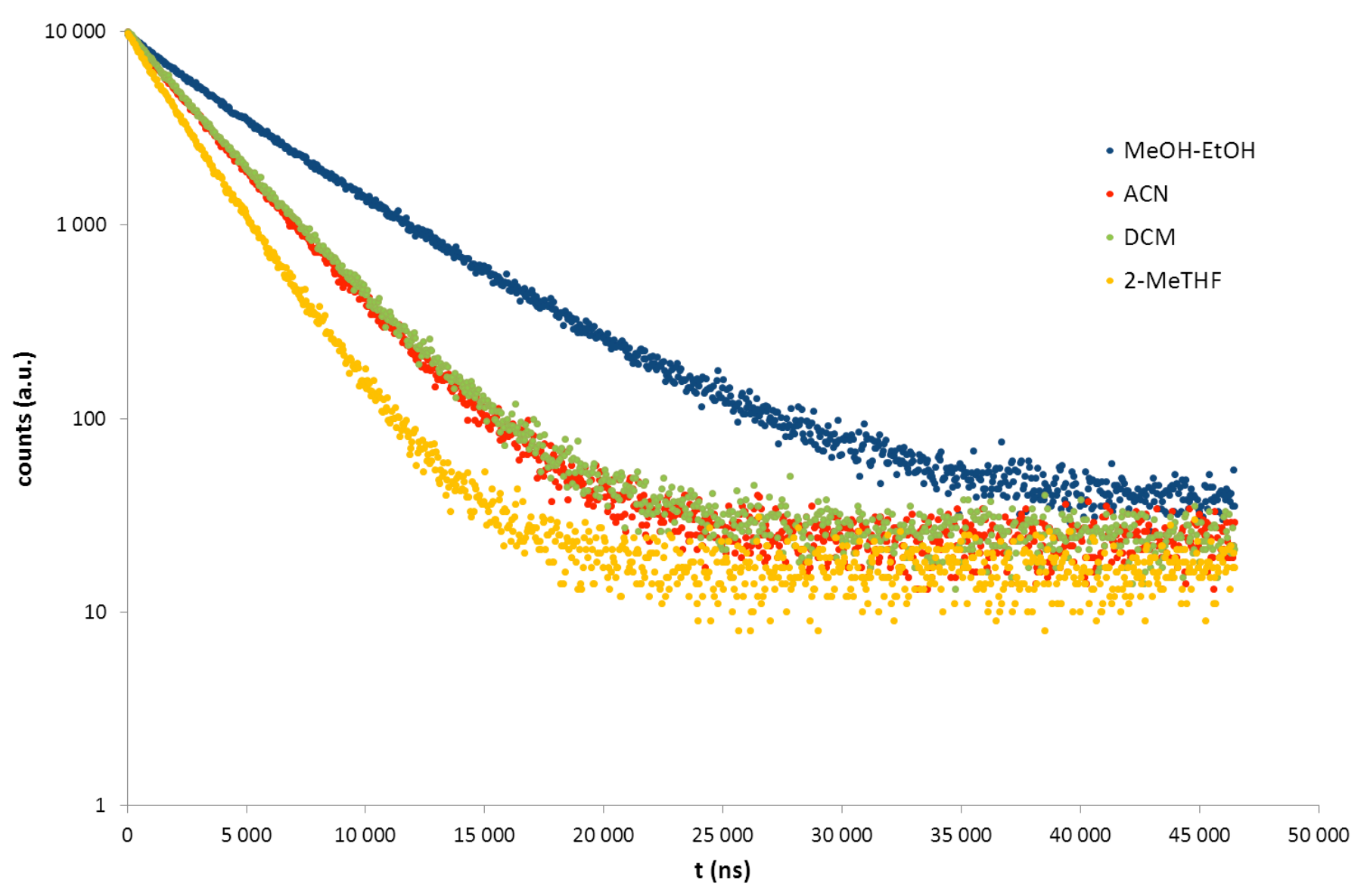

Figure S7. Emission decays of TBA[1] in the different solvents. The decays were recorded at room temperature by exciting the solution $(\mathrm{A} \sim 0.1)$ at $405 \mathrm{~nm}$ and the photons between 475 and $525 \mathrm{~nm}$ were collected. 


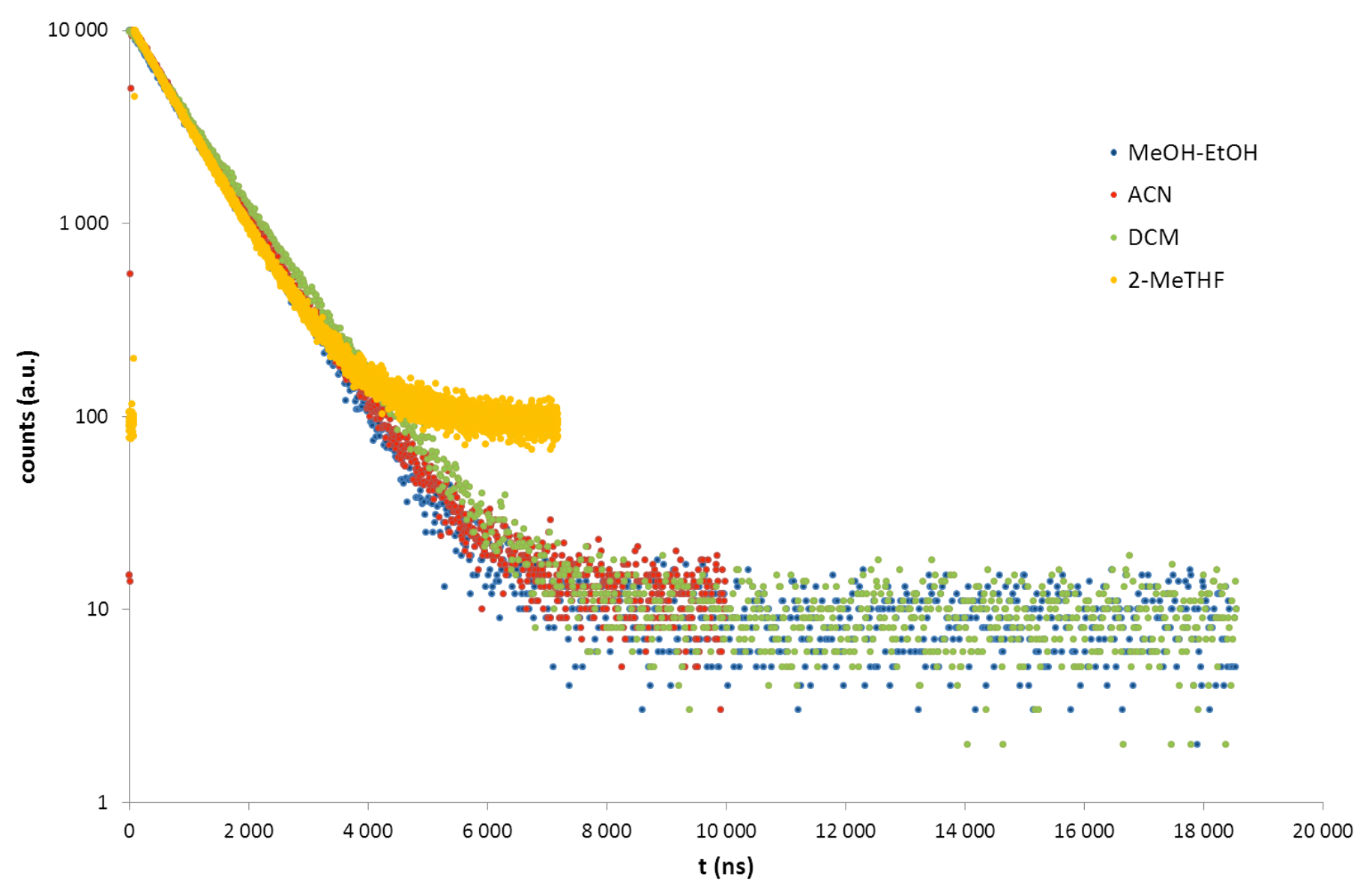

Figure S8. Emission decays of $[\mathbf{2}] \mathbf{C l}_{\mathbf{2}}$ in the different solvents. The decays were recorded at room temperature by exciting the solution (A 0.1) at $405 \mathrm{~nm}$ and the photons between 525 and $575 \mathrm{~nm}$ were collected. The lifetime of the solution in 2-MeTHF was recorded at $630 \mathrm{~nm}$ on $[\mathbf{2}]\left(\mathbf{P F}_{\mathbf{6}} \mathbf{2}_{\mathbf{2}}\right.$. 


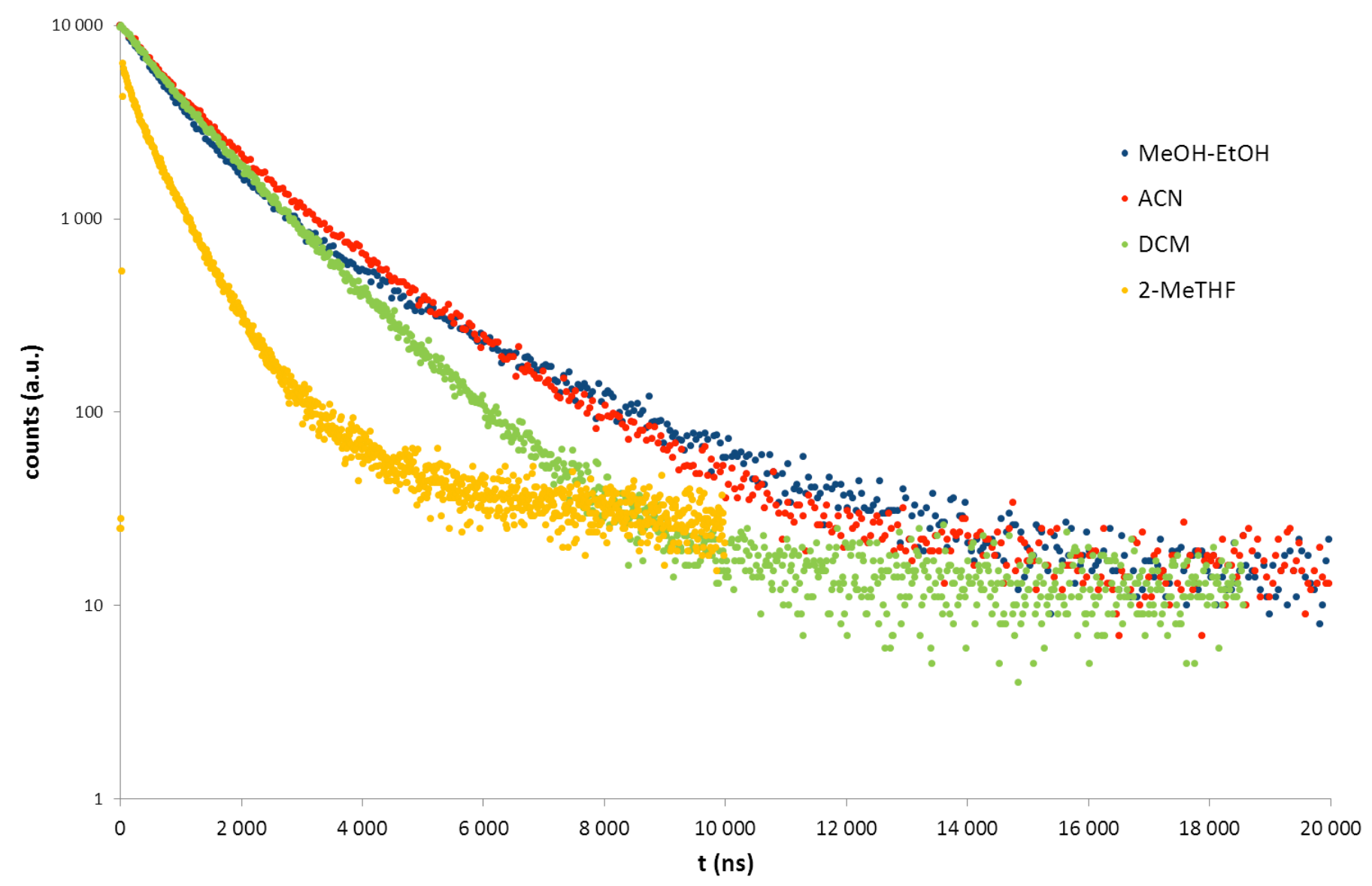

Figure S9. Emission decays of $[2][1]_{2}$ in the different solvents. The decays were recorded at room temperature by exciting the solution $(\mathrm{A} \sim 0.1)$ at $405 \mathrm{~nm}$ and the photons between 475 and $525 \mathrm{~nm}$ were collected. 


\section{CIE xy chromaticity diagram:}

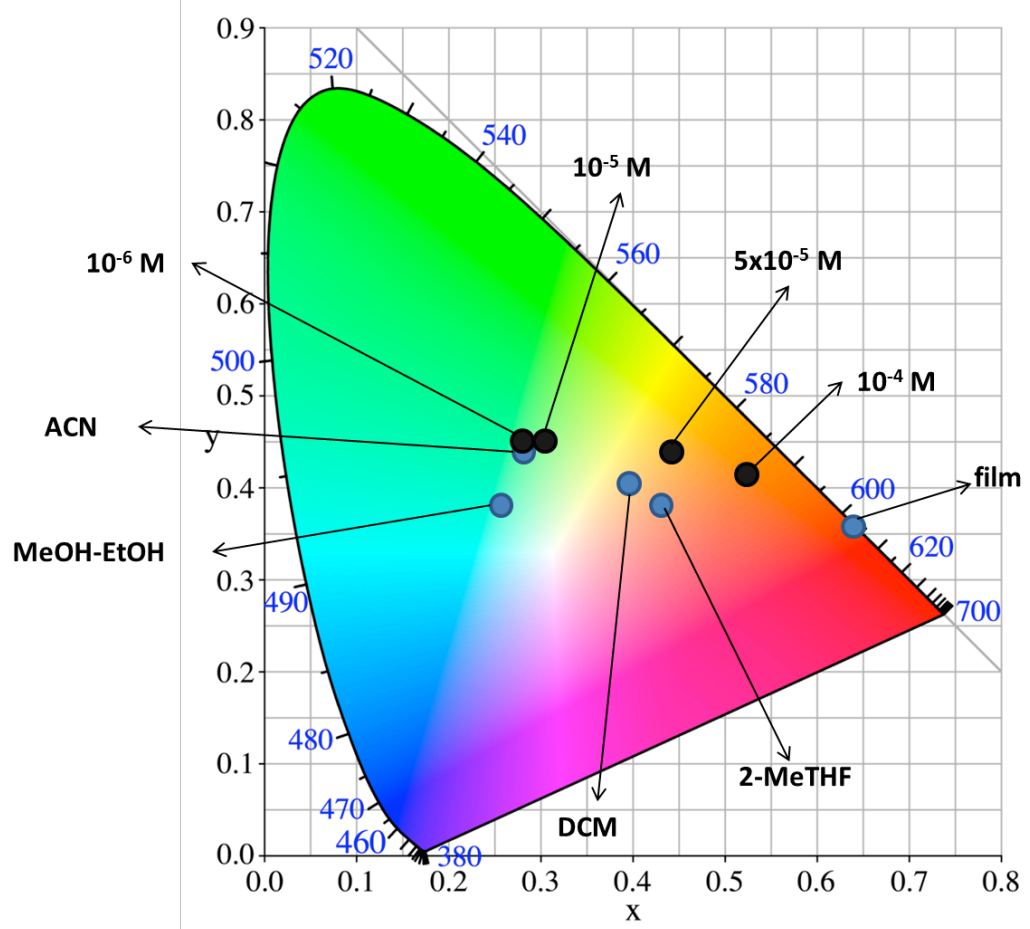

Figure S10. CIE colour diagram representing the $\mathrm{x}$ and $\mathrm{y}$ coordinates obtained from the emission spectra of the soft salt in different conditions (indicated for each point on the graph).

Table S2. xy coordinates for the emission spectra of the soft salt in the indicated conditions.

\begin{tabular}{|c|c|c|c|c|c|c|c|c|}
\hline \multicolumn{9}{|c|}{ Conditions } \\
\hline МeOH-EtOH & $\mathbf{A C N}$ & DCM & 2-МеТНF & solid film & $10^{-6} M^{a}$ & $10^{-5} \mathrm{M}^{\mathrm{a}}$ & $5 \times 10^{-5} M^{a}$ & $10^{-4} \mathrm{M}^{\mathrm{a}}$ \\
\hline 0.260 & 0.267 & 0.401 & 0.435 & 0.663 & 0.279 & 0.294 & 0.435 & 0.521 \\
\hline 0.384 & 0.436 & 0.400 & 0.383 & 0.336 & 0.453 & 0.434 & 0.428 & 0.417 \\
\hline
\end{tabular}

${ }^{a}$ in ACN solution

\section{References:}

(1) Nazeeruddin, M. K.; Humphry-Baker, R.; Berner, D.; Rivier, S.; Zuppiroli, L.; Graetzel, M. J. Am. Chem. Soc. 2003, 125, 8790.

(2) Schwalbe, M.; Schäfer, B.; Görls, H.; Rau, S.; Tschierlei, S.; Schmitt, M.; Popp, J.; Vaughan, G.; Henry, W.; Vos, J. G. Eur. J. Inorg. Chem. 2008, 2008, 3310.

(3) Crosby, G. A.; Demas, J. N. J. Phys. Chem. 1971, 75, 991.

(4) Garces, F. O.; Watts, R. J. Magn. Reson. Chem. 1993, 31, 529. 